\title{
Penentuan Jumlah Operator Untuk Mengurangi Keterlambatan pada Proses Pengemasan Menggunakan Simulasi ProModel
}

\section{Determining the Number of Operators to Reduce the Delay of Packaging Process Using ProModel Simulation}

\author{
Mirna Lusiani $^{1 *}$, Kenrick Filbert ${ }^{1}$ \\ ${ }^{1}$ Program Studi Teknik Industri, Universitas Bunda Mulia, Jl. Lodan Raya No. 2 Ancol, Jakarta Utara 14430, \\ Indonesia
}

Diterima: 3 Juni, 2019 / Disetujui: 1 Agustus, 2019

\begin{abstract}
In the current era of modernization, the development of the cosmetic industry in the world is developing very rapidly. One of the cosmetics that is the main requirement for women is lipstick. PT. Cedefindo is one of the cosmetic manufacturers that produce SASC lipstick. During 2017, there were problems in the lipstick packaging process. Based on the results of identification, the delay is caused by the buildup during the weighing process so that the next process becomes slow and sometimes makes the operator idle. The consequence that arises is often not achieving daily production targets. Therefore, this research aims to reduce the delay in the lipstick packaging process, especially the lipstick packaging section. In evaluating and analyzing the lipstick packaging system, research uses system simulation with the help of ProModel software. The result shows that adding would reduce the delay in the lipstick packaging process. Minimizing the production costs related to the packaging process is conducted by reducing operator unused work shifts. Therefore, adding some operators can reduce production costs especially on operator salaries up to $75 \%$. The feasible solution is to assign 3 operators on low demand rate, 4 operators at normal demand rate and high demand rate.
\end{abstract}

Keywords: Simulation, Stacking, Utilities, Promodel.

\begin{abstract}
ABSTRAK
Di era modernisasi saat ini, perkembangan industri kosmetik di dunia berkembang sangat pesat. Salah satu kosmetik yang menjadi syarat utama bagi wanita adalah lipstik. PT. Cedefindo adalah salah satu produsen kosmetik yang memproduksi lipstik SASC. Selama 2017, ada masalah dalam proses pengemasan lipstik. Berdasarkan hasil identifikasi, keterlambatan disebabkan oleh penumpukan selama proses penimbangan sehingga proses selanjutnya menjadi lambat dan terkadang membuat operator menganggur. Konsekuensi yang muncul seringkali tidak mencapai target produksi harian. Oleh karena itu, penelitian ini bertujuan untuk mengurangi keterlambatan dalam proses pengemasan lipstik, khususnya bagian pengemasan lipstik. Dalam mengevaluasi dan menganalisis sistem pengemasan lipstik, penelitian menggunakan simulasi sistem dengan bantuan perangkat lunak ProModel. Hasilnya menunjukkan bahwa menambahkan operator akan mengurangi keterlambatan dalam proses pengemasan lipstik. Meminimalkan biaya produksi terkait dengan proses pengemasan dilakukan dengan mengurangi shift kerja yang tidak digunakan operator. Oleh karena itu, menambahkan beberapa operator dapat mengurangi biaya produksi terutama pada gaji operator hingga 75\%. Solusi yang layak adalah menetapkan 3 operator pada tingkat permintaan rendah, 4 operator pada tingkat permintaan normal dan tingkat permintaan tinggi.
\end{abstract}

Kata Kunci: Simulasi, Penumpukan, Utilitas, ProModel

\section{PENDAhUluaN}

Kosmetik dan alat kecantikan sudah menjadi kebutuhan utama bagi kaum wanita terutama lipstik. PT. Cedefindo merupakan salah satu produsen kosmetik dan alat kecantikan dimana salah satunya adalah lipstik. Permasalahan yang dihadapi oleh PT. Cedefindo adalah keterlambatan proses kemas lipstik.

*email: mirna_lusiani@yahoo.com 
Bedasarkan data historis, selama tahun 2017 dari bulan Juni hingga bulan November selalu terjadi keterlambatan proses kemas. Berdasarkan identifikasi awal, adanya penumpukan pada proses penimbangan ini yang menyebabkan proses berikutnya menjadi lambat sehingga tidak tercapainya target produksi harian.Untuk itu, perlunya dilakukan penelitian untuk mengatasi permasalahan ini.

Beberapa penelitian telah dilakukan berkaitan dengan permasalahan keterlambatan dalam suatu proses didalam sistem. Penelitian sebelumnya membahas keterlambatan dalam proses servis perbaikan listrik menggunakan simulasi sistem untuk meningkatkan utilitas sumber daya (Choudhari dan Gajjar, 2018). Penelitian lain berfokus pada permasalahan tingkat layanan (service level) rendah dan sumber daya yang tidak memadai menggunakan optimasi dan simulasi (Keeling, Brown dan Kros, 2013). Tingkat layanan juga ditinjau dari aspek komunikasi yang dapat memberikan kesan positif kepada pelanggan (Tarsani, 2016). Simulasi juga digunakan dalam menanggulangi permasalahan bottleneck dalam sistem (Penazzi et al., 2017). Berdasarkan dari penelitian terdahulu maka penelitian ini bertujuan untuk mengatasi permasalahan keterlambatan proses kemas menggunakan simulasi.

Sistem didefinisikan sebagai kumpulan dari beberapa entitas yang berperilaku dan saling berinteraksi bersama untuk mencapai tujuan yang logis. Kumpulan dari beberapa entitas, beraktivitas dan berinteraksi bersama yang membentuk sebuah sistem memiliki tujuan tertentu (Soegiharto dan Asih, 2014). Simulasi merupakan salah satu cara untuk menyelesaikan berbagai masalah dalam industri di kehidupan sehari-hari (Trenggonowati, 2016). Pendekatan yang dapat digunakan dalam penyelesaian masalah jangka panjang dapat menggunakan simulasi. Berikut merupakan langkah-langkah dalam membuat simulasi yaitu (Puteri dan Sudarwati, 2016):

1. Perencanaan studi

Langkah awalnya perencanaan studi dari simulasi tentang ruang lingkup dari sebuah proyek. Sebuah proses perencanaan proyek yang harus dikembangkan secara nyata, jelas dan mudah dipahami.

2. Mendefinisikan sistem

Langkah kedua mengidentifikasi sistem dengan detail yang dimodelkan sehingga mudah untuk disimulasikan.
3. Menyusun model

Langkah berikutnya menyusun model simulasi dari sistem yang sudah berjalan saat ini.

4. Melakukan eksperimen

Pada langkah ini dilakukan eksperimen pada model simulasi yang dibuat termasuk penentuan atribut simulasi seperti waktu persiapan, replikasi ataupun metode perancangan eksperimen.

5. Menganalisis output

Menganalisis output dapat dilakukan dengan cara verifikasi dan validasi model. Verifikasi berhubungan dengan model saat ini telah benar diterjemahkan kedalam bahasa pemrograman (Choudhari dan Gajjar, 2018). Verifikasi model dilakukan dengan menggunakan trial and error pada process logic pada menu debug di aplikasi ProModel, apabila tidak ditemukan adanya debug maka dapat dibilang bahwa model sudah terverifikasi.

Uji validasi dilakukan dengan bantuan statistik dengan menggunakan berbagai uji, salah satunya dengan menggunakan uji $t$ (Profita, Utomo dan Fachriansyah, 2017) untuk menghitung rata-rata dan uji $X^{2}$ untuk menghitung standar deviasi.

6. Melaporkan Hasil

Langkah terakhir mempresentasikan hasil kesimpulan dan membuat rekomendasi agar dapat dilakukan pengambilan keputusan.

Beberapa elemen penting pada sebuah sistem yang dapat didefinisikan oleh ProModel, yakni (Situmorang, 2014):

1. Location

2. Entity

3. Path Networks

4. Resources

5. Arrivals

6. Processing

7. Variable (Global)

\section{METODOLOGI}

Metodologi dari penelitian ini tertuang dalam Gambar 1. Penelitian ini diawali dengan mengindetifikasi masalah yang terjadi di perusahaan, yakni terjadinya penumpukkan pada saat pengemasan lipstik. Setelah melakukan pengumpulan data dengan data primer dan sekunder selanjutnya data tersebut diuji kecukupan data. Kemudian data tersebut diolah menggunakan simulasi. Setelah 
mendapatkan kondisi nyata di uji verifikasi dan validasi untuk membuat simulasi usulan.

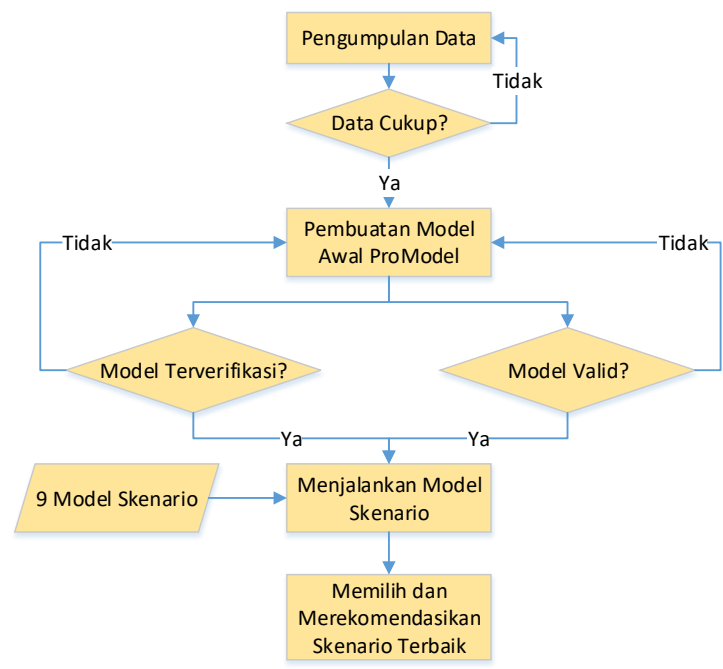

Gambar 1. Diagram Alir Metodologi Penelitian

\section{HASIL DAN PEMBAHASAN}

Tabel 1 merupakan data historis lipstik SASC tahun 2017. Pada Bulan Juni 2017 terdapat jumlah permintaan sebanyak 1376, 1378, 1412, 1407, 1344 unit. Pada Bulan Juli terdapat pemesanan sebesar 1726 unit, untuk Bulan Agustus terdapat pemesanan sebesar 1668 unit, untuk Bulan September ada pemesanan sebesar 1642 dan 1661 unit, dan pada Bulan November terdapat pesanan sebesar 1678, 1075, $1689,737,1295$ unit.

Tabel 1. Data Historis Lipstik SASC

\begin{tabular}{clc}
\hline No & Bulan & Jumlah Permintaan (unit) \\
\hline $\mathbf{1}$ & Juni & 1376 \\
$\mathbf{2}$ & Juni & 1378 \\
$\mathbf{3}$ & Juni & 1412 \\
$\mathbf{4}$ & Juni & 1407 \\
$\mathbf{5}$ & Juni & 1344 \\
$\mathbf{6}$ & Juli & 1726 \\
$\mathbf{7}$ & Agustus & 1668 \\
$\mathbf{8}$ & September & 1642 \\
$\mathbf{9}$ & September & 1661 \\
$\mathbf{1 0}$ & November & 1678 \\
$\mathbf{1 1}$ & November & 1075 \\
$\mathbf{1 2}$ & November & 1689 \\
$\mathbf{1 3}$ & November & 737 \\
$\mathbf{1 4}$ & November & 1295 \\
\hline
\end{tabular}

Pengumpulan data waktu observasi dilakukan dengan mengamati 9 operasi dengan standar waktu berbeda-beda antar operasi. Waktu observasi dihitung dengan menggunakan stopwatch sebanyak 10 kali dan didapat hasil seperti pada Tabel 2.

\subsection{Entity Flow Diagram}

Entity Flow Diagram seperti terlihat pada Gambar 2 merupakan urutan proses yang dilalui entitas didalam sistem. Dari entity flow diagram terlihat bahwa lipstik datang dari bagian produksi dengan distribusi $\mathrm{N}(1435,278.6)$. Kemudian menuju proses filling dengan lama proses sebesar L $(4.82,0.72)$ menit. Setelah itu, menuju proses timbang. Apabila dari proses timbang tidak memenuhi persyaratan maka harus dilakukan perbaikan. Jika lolos persyaratan maka lanjut ke proses pemasangan brush. Setelah pemasangan brush dilanjutkan ke proses batching. Dari proses batching dilanjutkan ke tahap pemasangan stiker. Dari pemasangan stiker kemudian lipstik dilakukan inspeksi. Apabila tidak lolos inspeksi maka dilakukan perbaikan terlebih dahulu sebelum ke proses selanjutnya. Jika lolos inspeksi maka dilanjutkan ke meja packing. Kemudian dilanjutkan kembali ke proses akhir yaitu penimbangan akhir.

\subsection{Simulasi Usulan}

Simulasi usulan digunakan beberapa skenario guna mendapatkan beberapa hasil untuk dipertimbangkan, seperti ditampilkan pada Tabel 3. Simbol huruf mewakili kondisi permintaan dari lipstik. Huruf A menggambarkan kondisi "normal demand", huruf B menggambarkan kondisi "high demand", dan huruf C menggambarkan kondisi "low demand".

Untuk simbol angka, menunjukkan penambahan jumlah operator untuk operator pemasangan brush. Sebagai contoh, skenario 1A berarti pada kondisi "normal demand" dengan jumlah operator ditambahkan 1 orang sehingga jumlah operator menjadi 2 orang. Skenario 2B berarti pada kondisi "high demand" dengan jumlah operator ditambahkan 2 orang sehingga jumlah operator menjadi 3 orang. Penjelasan skenario ini ditunjukkan pada Tabel 4. 
Tabel 2. Data Observasi Lipstik SASC

\begin{tabular}{lrrrrrr}
\hline \multicolumn{1}{c}{ Operation } & Std time $(\mathbf{s})$ & $\mathbf{1}$ & $\mathbf{2}$ & $\mathbf{3}$ & $\mathbf{4}$ & $\mathbf{5}$ \\
\hline Filling & 5,00 & 5,2 & 6,2 & 4,0 & 5,6 & 4,4 \\
Timbang & 2,50 & 1,9 & 3,0 & 2,2 & 3,1 & 2,5 \\
Perbaikan & 20,00 & 19,0 & 21,7 & 19,1 & 18,2 & 20,8 \\
Pasang brush & 3,75 & 4,4 & 3,3 & 4,8 & 3,0 & 4,3 \\
Batching container & 4,00 & 3,1 & 3,0 & 3,6 & 3,8 & 4,4 \\
Pasang stiker bottom & 4,00 & 5,4 & 4,0 & 3,6 & 4,5 & 3,9 \\
Inspeksi & 4,00 & 4,4 & 3,1 & 3,3 & 4,1 & 4,6 \\
Masuk inner doos & 3,75 & 3,5 & 4,5 & 4,1 & 3,9 & 4,4 \\
Timbang akhir & 3,50 & 4,3 & 3,1 & 4,8 & 3,7 & 4,2 \\
Filling & 5,00 & 4,3 & 5,2 & 4,9 & 4,0 & 4,4 \\
Timbang & 2,50 & 2,2 & 2,6 & 2,4 & 3,1 & 2,4 \\
Perbaikan & 20,00 & 18,5 & 21,1 & 20,3 & 19,8 & 27 \\
Pasang brush & 3,75 & 4,2 & 4,3 & 3,9 & 4,0 & 3,5 \\
Batching container & 4,00 & 3,5 & 3,0 & 3,9 & 4,5 & 3,8 \\
Pasang stiker bottom & 4,00 & 3,1 & 4,2 & 4,7 & 4,6 & 3,9 \\
Inspeksi & 4,00 & 3,2 & 3,6 & 3,6 & 3,5 & 3,3 \\
Masuk inner doos & 3,75 & 4,7 & 4,8 & 3,8 & 3,3 & 4,6 \\
Timbang akhir & 3,50 & 4,9 & 4,0 & 3,8 & 3,3 & 3,4 \\
\hline
\end{tabular}

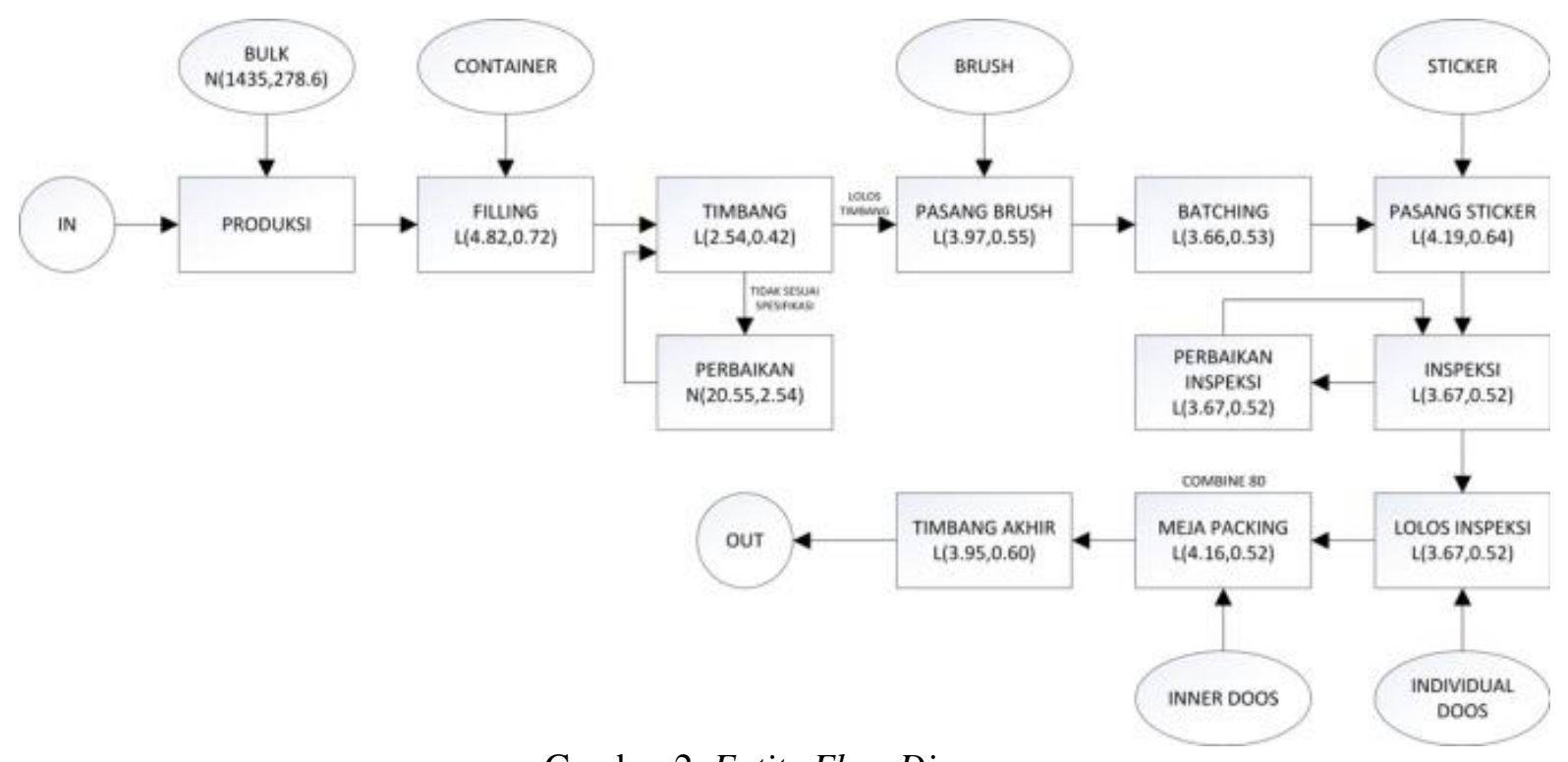

Gambar 2. Entity Flow Diagram

Dari hasil simulasi dengan berbagai macam skenario, maka didapat hasil utilitas operator pasang brush seperti pada Tabel 5. Dari tabel terlihat bahwa pada skenario 1A dimana kondisi "normal demand" dengan jumlah operator sebanyak 2 orang maka utilisasi operator sebesar $98 \%$. Jika pada kodisi yang sama "normal demand" dengan ditambahkan 1 operator lagi menjadi 3 orang (skenario $2 \mathrm{~A}$ ) maka utilisasi operator turun menjadi $85 \%$. Dari tabel dapat terlihat dengan kondisi permintaan yang sama, utilisasi dari operator akan menurun dengan adanya penambahan jumlah operator.
Tabel 3. Skenario Usulan

\begin{tabular}{cccc}
\hline Skenario & $\mathbf{1}$ & $\mathbf{2}$ & $\mathbf{3}$ \\
\hline A & $\mathbf{1 A}$ & $\mathbf{2 A}$ & $\mathbf{3 A}$ \\
B & $\mathbf{1 B}$ & $\mathbf{2 B}$ & $\mathbf{3 B}$ \\
C & $\mathbf{1 C}$ & $\mathbf{2 C}$ & $\mathbf{3 C}$
\end{tabular}

Tabel 4. Keterangan Penggabungan Skenario

\begin{tabular}{ll}
\hline Simbol & \multicolumn{1}{c}{ Keterangan } \\
\hline 1A & $\begin{array}{l}\text { Normal Demand dengan operator } \\
\text { pasang brush 2 }\end{array}$ \\
1B & $\begin{array}{l}\text { High Demand dengan operator pasang } \\
\text { brush 2 } \\
\text { Low Demand dengan operator pasang } \\
\text { brush 2 }\end{array}$ \\
\hline
\end{tabular}




\begin{tabular}{|c|c|}
\hline Simbol & Keterangan \\
\hline $2 A$ & $\begin{array}{l}\text { Normal Demand dengan operator } \\
\text { pasang brush } 3\end{array}$ \\
\hline 2B & $\begin{array}{l}\text { High Demand dengan operator pasang } \\
\text { brush } 3\end{array}$ \\
\hline $2 \mathrm{C}$ & $\begin{array}{l}\text { Low Demand dengan operator pasang } \\
\text { brush } 3\end{array}$ \\
\hline $\mathbf{3 A}$ & $\begin{array}{l}\text { Normal Demand dengan operator } \\
\text { pasang brush } 4\end{array}$ \\
\hline 3B & $\begin{array}{l}\text { High Demand dengan operator pasang } \\
\text { brush } 4\end{array}$ \\
\hline $3 C$ & $\begin{array}{l}\text { Low Demand dengan operator pasang } \\
\text { brush } 4\end{array}$ \\
\hline
\end{tabular}

Tabel 5. Perbandingan Simulasi Usulan Berdasarkan Operator

\begin{tabular}{cc}
\hline Skenario & $\begin{array}{c}\text { Utilitas Operator Pasang Brush } \\
(\boldsymbol{\%})\end{array}$ \\
\hline 1A & 98 \\
1B & 100 \\
1C & 62 \\
2A & 85 \\
2B & 94 \\
2C & 44 \\
3A & 66 \\
3B & 73 \\
3C & 32 \\
\hline
\end{tabular}

Tabel 6. Perbandingan Simulasi Usulan Berdasarkan Waktu

\begin{tabular}{ll}
\hline Skenario & Waktu Selesai \\
\hline 1A & Hari $1-15.28$ \\
2A & Hari $1-13.15$ \\
3A & Hari $1-13.11$ \\
1B & Hari $1-20.46$ \\
2B & Hari $1-16.36$ \\
3B & Hari $1-16.34$ \\
1C & Hari $1-09.34$ \\
2C & Hari $1-08.59$ \\
3C & Hari $1-09.00$ \\
\hline
\end{tabular}

Hasil perbandingan simulasi usulan berdasarkan waktu ditampilkan pada Tabel 6 . Dapat dilihat dari semua hasil skenario menunjukkan lipstik selesai di hari pertama shift pertama untuk jumlah permintaan yang normal, untuk skenario jumlah permintaan yang sedang tinggi selesai di hari pertama shift kedua, dan untuk skenario jumlah permintaan yang sedang rendah semua selesai di hari pertama shift pertama.

\subsection{Pembahasan}

Hasil paling optimum untuk skenario kondisi normal demand adalah 2A karena waktu selesai pengerjaannya selesai lebih cepat, untuk kondisi high demand hasil yang paling optimum adalah $2 \mathrm{~B}$ maupun $2 \mathrm{C}$ hasilnya tidak berbeda signifikan maka dapat dipilih dari kedua itu, untuk kondisi low demand hasil yang optimum adalah $2 \mathrm{~B}$ dan 2C karena hasilnya tidak berbeda signifikan. Dari hasil skenario penambahan jumlah operator pasang brush maka didapatkan hasil utilisasi yang paling optimum adalah pada 3A, 3B dan 2C. Artinya, pada permintaan low demand cukup memakai 3 operator pasang brush, untuk permintaan normal dan high demand memakai 4 operator pasang brush.

\section{SIMPULAN}

Proses pengemasan lipstik kondisi saat ini memiliki masing-masing satu operator untuk setiap stasiun kerja, keterlambatan proses pengemasan yang disebabkan oleh operator pasang brush yang memiliki utilitas tinggi. Usulan skenario pada kondisi usulan yaitu dengan menambah jumlah operator pasang brush pada tiap skenario. Selain itu, model juga diuji dengan tingkat kedatangan produk pada saat permintaan normal, tinggi maupun rendah.

Cara mempercepat waktu proses pengemasan lipstik SASC adalah dengan cara menggunakan 4 operator pasang brush agar waktu pengerjaan menjadi lebih singkat. Cara mengurangi biaya produksi pada proses pengemasan lipstik dengan mengurangi shift kerja operator lipstik SASC yang awalnya 4 shift menjadi 1 shift dengan menambah operator pasang brush sehingga dapat mengurangi biaya produksi khususnya pada gaji operator listrik SASC hingga $75 \%$ sehingga setelah proses lipstik SASC selesai, mesin dapat memproduksi lipstik yang berbeda dengan tipe yang sama. Jumlah operator pasang brush pada kondisi usulan proses pengemasan lipstik SASC adalah 3 operator pasang brush untuk low demand, 4 operator pasang brush untuk normal dan high demand.

\section{DAFTAR PUSTAKA}

Choudhari, S. dan Gajjar, H. (2018) "Simulation Modeling for Manpower Planning in Electrical Maintenance Service Facility," Business Process Management Journal, 24(1), hal. 89-104. doi: 10.1108/BPMJ06-2016-0125.

Keeling, K. B., Brown, E. dan Kros, J. F. (2013) "Using Process Capability Analysis and Simulation to Improve Patient Flow," Applications of Management Science. 
Emerald Group Publishing Limited, 16, hal. 219-229. doi: 10.1108/S02768976(2013)0000016015.

Penazzi, S. et al. (2017) "Design and Control of Food Job-Shop Processing Systems: A Simulation Analysis in the Catering Industry," International Journal of Logistics Management, 28(3), hal. 782797. doi: 10.1108/IJLM-11-2015-0204.

Profita, A., Utomo, D. S. dan Fachriansyah, F. (2017) "Optimasi Manajemen Persediaan Darah Menggunakan Simulasi Monte Carlo," Journal of Industrial Engineering Management, 2(1), hal. 15-24. doi: 10.33536/jiem.v2i1.101.

Puteri, R. A. M. dan Sudarwati, W. (2016) "Pengukuran Line Balancing dan Simulasi Promodel di PT. Caterpillar Indonesia," Jurnal Integrasi Sistem Industri, 3(2), hal. 15-22. Tersedia pada: https://jurnal.umj.ac.id/index.php/jisi/arti cle/view/1043.
Situmorang, T. (2014) "Simulasi Sistem Produksi Crude Palm Oil pada PT. Perkebunan Nusantara XIII PMS Ngabang Menggunakan Metode Arena dan ProModel," Jurnal TIN Universitas Tanjungpura, 1(3), hal. 13-17.

Soegiharto, T. S. dan Asih, A. M. S. (2014) "Simulasi Aliran Pasien Rawat Inap Untuk Mengurangi Bottleneck," Jurnal Teknosains, 4(1), hal. 84-92. doi: 10.22146/teknosains.6051.

Tarsani (2016) "Peran Customer Service dalam Meningkatkan Kepuasan Pelanggan Melalui Pendekatan Komunikasi Antar Pribadi," Bricolage, 2(1), hal. 46-55. doi: 10.30813/bricolage.v2i01.833.

Trenggonowati, D. L. (2016) "Simulasi Sistem Proses Produksi di PT. Jakarta Cakratunggal Steel Mills," Jurnal Ilmiah Teknik Industri, 4(1), hal. 36-46. doi: 10.24912/jitiuntar.v4i1.462. 